brasileira em função da tendência internacional, é preciso observar que foi nessa área de conhecimento, particularmente no campo das ciências biomédicas, que teve início, nos primeiros anos desse século, o processo de organização institucional da pesquisa científica no Brasil. $O$ bom desempenho da pesquisa biomédica brasileira também pode ser explicado por sua trajetória institucional, e para isso não faltam excelentes trabalhos de cunho histórico e sociológico.

A ciência brasileira perfilada no livro de Leopoldo de Meis e Jacqueline Leta é aquela que circula por algum dos 7.421 periódicos científicos indexados pelo ISI. Como é extremamente baixo o número de revistas brasileiras indexadas (apenas 12 no período 1981-93, todas pertencentes às ciências biomédicas), essa ciência brasileira é, de fato, internacionalizada, seus produtos estão dirigidos à comunidade científica internacional. Esse é o dilema das comunidades científicas dos países periféricos, cuja busca da autonomia institucional e legitimidade social em seus respectivos países depende cada vez mais do grau de credibilidade alcançada junto ao mundo científico dos países centrais.

Luiz Otávio Ferreira Pesquisador da Casa de Oswaldo Cruz

\section{QUEBRANDO O SILÊNCIO: MULHERES E AIDS NO BRASIL}

\author{
Richard Parker e Jane Galvão (orgs.) \\ Rio de Janeiro, Relume-Dumará/Abia/IMS/ \\ UERJ, 1996
}

Após mais de uma década da descrição dos primeiros casos de Aids, muito já se disse, escreveu e publicou a seu respeito. Ainda assim, o assunto parece inesgotável. E, se no Brasil (bem como em vários outros países), a Aids tem sido considerada uma doença predominantemente masculina, nem mesmo a sua maior visibilidade entre as mulheres vem mudando esta vinculação. Há, no que diz respeito à Aids entre as mulheres, um silêncio - o mesmo que tradicionalmente cerca questões relacionadas à sexualidade e à saúde femininas.
Assim, este sétimo volume da coleção História Social da Aids, organizado por Richard Parker e Jane Galvão, vem não preencher este vácuo, mas, antes, evidenciá-lo. O pioneirismo da publicação já transparece no título: Quebrando o silêncio: mulheres e Aids no Brasil. $\mathrm{Na}$ introdução, os organizadores afirmam, logo na primeira frase: "Há mais de uma década, as complexas questões que vinculam a epidemia de HIV/Aids às mulheres vêm sendo envolvidas por um silêncio de proporções verdadeiramente inacreditáveis" (p. 7). Silêncio presente não apenas no discurso popular, mas também nas políticas públicas e nos projetos de ONGs voltados ao enfrentamento da epidemia. Nesse contexto, o discurso de que "a Aids é risco de todos" contrapõe-se à ausência de medidas efetivas no que diz respeito às mulheres.

Os artigos contidos no livro abordam desde um perfil do desenrolar da Aids no Brasil, com ênfase na presença feminina na epidemia, incluindo apresentação de dados epidemiológicos, até discussões sobre sexualidade feminina e uso de drogas entre mulheres.

$\mathrm{Na}$ introdução, os organizadores destacam como têm sido limitadas (e até inadequadas) as intervenções ao nível de prevenção direcionadas às mulheres, tanto no que diz respeito a campanhas na mídia quanto a serviços e programas voltados à saúde da mulher. Assim, afirmam os organizadores, "em meados dos anos 90 , a Aids entre as mulheres brasileiras apresentase como uma epidemia fora de controle" (p. 11).

A partir daí, o livro é dividido em três blocos. No primeiro, 'A trajetória feminina da epidemia', é oferecido ao leitor um panorama do desenvolvimento da epidemia de Aids, com ênfase na presença feminina. No segundo, '(Con)vivendo com Aids', são abordadas questões sobre as mulheres que têm a Aids perto de si, sejam soropositivas ou companheiras de pessoas com HIV/Aids. No terceiro, 'Políticas de omissão - políticas de prevenção', são discutidas as possibilidades de prevenção da Aids na população feminina e a atuação de grupos voltados à mulher.

Apesar desta divisão, os temas abordados nos artigos se interpenetram. No primeiro texto, Regina Barbosa e Wilza Villela fazem uma breve descrição da epidemia para, a seguir, discutir o 
silêncio sobre a presença do feminino nas estratégias de prevenção. Abrem espaço para uma discussão sobre sexualidade feminina e risco, incluindo comentários sobre negociação do uso da camisinha e métodos contraceptivos, sobre gravidez e aborto, além de questões sobre estratégias de prevenção voltadas à população feminina.

Já no texto de Naila J. Seabra Santos, também nesta primeira parte, são apresentados, de forma bastante didática, dados epidemiológicos sobre Aids entre as mulheres de São Paulo. A autora traça um perfil da epidemia entre essas mulheres, destacando que, mesmo com a entrada das mulheres no circuito da Aids, a epidemia tem sido entendida como uma patologia da população masculina.

O terceiro artigo, de Francisco Inácio Bastos, aborda a questão da mulher usuária de drogas injetáveis. O autor destaca que pouco se sabe sobre estas mulheres não só no Brasil, como em todo o mundo, e faz uma comparação entre dados europeus e brasileiros a respeito do uso de drogas injetáveis, em termos gerais. O autor destaca também a importância dos usuários de drogas injetáveis na epidemia, no âmbito da transmissão heterossexual, além de ressaltar a especificidade do assunto, afirmando ser "urgente que definamos protocolos de pesquisa que tematizem, especificamente, a mulher usuária, como também a parceira do usuário de drogas" (p. 72).

O primeiro artigo da segunda parte, que versa sobre mulheres (con)vivendo com Aids, aborda a questão da assistência ao portador de HIV/ doente de Aids. A autora, Elizabeth Moreira dos Santos, utiliza-se, para a discussão, da história de uma paciente hipotética, de nome 'Rosa'. A partir da história de 'Rosa', a autora discute aspectos sócio-econômicos do país, a atenção à saúde feminina no Brasil, e a presença da Aids neste contexto.

Os outros dois artigos desta parte trabalham com entrevistas e depoimentos. O artigo de Kátia Guimarães traz comentários sobre a inclusão da mulher na epidemia e, com as entrevistas, discute temas como a estruturação da identidade feminina, os papéis masculinos $\mathrm{e}$ femininos, as negociações nas relações homem/ mulher, a "dupla moral sexual" e outros. Em sua conclusão, a autora comenta a mudança que vem se dando no panorama da epidemia, discutindo a diferenciação cultural masculino/feminino e ressaltando o "tradicional silêncio feminino".

No último artigo desta segunda parte, "A Aids entre as mulheres: reflexões sobre seus depoimentos', Naila J. Seabra Santos e Rosemeire Munhoz apresentam uma série de depoimentos de mulheres soropositivas. Abordam desde o momento em que as mulheres receberam o resultado do exame, suas reflexões sobre filhos e família e as negociações intracasal após o resultado, até discussões sobre o atendimento nos serviços de saúde e ONGs.

No primeiro artigo da terceira parte, que aborda os discursos sobre sexualidade e Aids, Donna Goldstein propõe uma questão: "pode ou não a mulher ter sexo seguro, dada a rede de relações em que ela se encontra?" (p. 137). A partir daí, a autora passa a cliscorrer sobre a "realidade da mulher", abordando temas como sistema de saúde, sexualidade, movimentos feministas e Aids, estratégias de proteção etc. Abrange também o contexto brasileiro da relação homem-mulher e as dicotomias presentes no feminino/masculino, utilizando-se de alguns depoimentos de mulheres para sua discussão.

No capítulo seguinte, 'Feminismo e Aids', Regina Barbosa já começa sua discussão mostrando o quanto o Brasil ainda é deficiente na área: "Falar sobre a relação entre feminismo e Aids é um desafio, pois significa discutir um tema a respeito do qual o movimento feminista, no Brasil, não tem experiência acumulada, demonstrando, inclusive, uma certa resistência a incorporá-lo à sua agenda" (p. 153). A autora apresenta um breve panorama da epidemia e, a partir daí, aprofunda-se na questão da mulher, comentando especificidades que apontam para um maior risco da mulher no que diz respeito à infecção pelo HIV, diagnóstico tardio e até nãodiagnóstico. Aqui, mais uma vez, estão presentes discussões sobre negociação do uso da camisinha e padrões de comportamento sexual.

Carmem Dora Guimarães é enfática já no título de seu artigo, 'Mas eu conheço ele!: um método de prevenção do HIV/Aids'. A autora fala do preconceito desencadeado no imaginário social da Aids, destacando a oposição entre Aids como risco de todos e a existência de grupos/ comportamentos de risco, além de discutir o destaque dado à responsabilidade individual nas 
estratégias de saúde. Ela apresenta reflexões sobre a percepção de risco das mulheres frente à epidemia, utilizando dois grupos: um, de mulheres sabidamente soropositivas e, outro, de mulheres "supostamente não infectadas pelo HIV" (p. 172). Ao longo do texto, aparecem comentários sobre a informação que as mulheres têm sobre a Aids, representações sobre a sexualidade feminina e como esses temas influenciam (ou não) a vida particular dessas mulheres. É no meio desses discursos que aparece a frase do título, "mas eu conheço ele!", indicando que conhecer o outro aparece, assim, como método de prevenção bastante usado contra a Aids. Algo que, no entanto, vai ser contraposto aos depoimentos das mulheres infectadas.

No texto de Wilza Vieira Villela, é abordada a questão da negociação sexual, dizendo, já no início, que o condom "é um método masculino que depende de um acordo prévio entre os parceiros" (p. 181). A autora trata de questões sobre gênero e sexualidade, comentando as relações entre um poder masculino e um contrapoder feminino, e discute a negociação sexual e suas condições assimétricas em relação ao homem e à mulher.

Já Tânia Di Giacomo do Lago abre seu texto dizendo que "a idéia de associar a prevenção de doenças sexualmente transmissíveis (DST) à prática da anticoncepção não é nova, embora atual" (p. 191). A partir desta frase, a autora discorre sobre as finalidades e caminhos da anticoncepção, listando vários métodos e discutindo sua utilização no âmbito das doenças sexualmente transmissíveis. A seguir, analisa a anticoncepção na realidade brasileira, comentando o perfil da utilização de métodos contraceptivos no país.

Trata-se, portanto, de um livro abrangente no que diz respeito à presença feminina na epidemia. Quebrando o silêncio traz sonoridade à visibilidade que a epidemia de Aids vem adquirindo entre as mulheres. É um livro que merece ser lido por todos aqueles que possam unir a estas as suas vozes e, quem sabe, finalmente encerrar o silêncio.

Andréa Rocha Ferreira aluna do Instituto de Medicina Social Universidade do Estado do Rio de Janeiro (IMS/UERJ)

\section{CIÊNCIA E SOCIEDADE NA TERRA DOS BANDEIRANTES: A TRAJETÓRIA DO INSTITUTO PASTEUR DE SÃo PAULO NO PERÍODO DE 1903 A 1916}

Luiz Antônio Teixeira

Rio de Janeiro, Editora Fiocruz, 1995

A história das ciências no Brasil, apesar do desenvolvimento significativo dos últimos anos, é uma área incipiente. Em especial, muitas das instituições científicas brasileiras estão ainda à espera de pesquisadores que se dediquem ao estudo de sua trajetória.

É com grande satisfação que vemos editado o livro de Luiz Antônio Teixeira, Ciência e sociedade na terra dos bandeirantes: a trajetória do Instituto Pasteur de São Paulo no período de 1903 a 1916, resultado de sua pesquisa para o mestrado realizada no Instituto de Medicina Social da Universidade do Estado do Rio de Janeiro (UERJ).

Neste texto, com estilo claro, de leitura agradável mas extremamente erudito e cuidadoso no desenvolvimento dos temas, o leitor acompanha a trajetória desta instituição científica tão pouco conhecida, mesmo de historiadores que se dedicam ao estudo das ciências no Brasil.

A discussão inicial sobre a escolha do objeto de estudo é bastante instigante e esclarecedora. Partindo de um levantamento historiográfico, o autor afirma que o Instituto Pasteur de São Paulo vem sendo ignorado pelos historiadores brasileiros, e conclui que estes, utilizando prioritariamente documentação oficial, têm privilegiado a atuação das instituições governamentais. E mais, têm contribuído para a construção de um consenso: o de que o Estado vem sendo o agente, quase que exclusivo, da implementação de atividades científicas no país.

Uma das contribuições a que este estudo se propõe é, assim, resgatar o papel que outros setores da sociedade brasileira tiveram no incentivo às práticas científicas. E, particularmente, chamar a atenção para a situação de uma instituição privada bastante atuante no cenário médico paulista do início do século XX.

Do ponto de vista metodológico, o autor pretende realizar um estudo de história 